\title{
Research and Analysis of Reasonable Increase Mechanism for Enterprise Salary under the Economic New Normal
}

\author{
Yan $\mathrm{Li}^{1, \mathrm{a}^{*}}$ \\ 1 Jincheng College of Sichuan University, Chengdu, Sichuan Province, China \\ a24526368@qq.com
}

Keywords: Economy; New normal; Enterprise; Enterprise; Reasonable increase

\begin{abstract}
The enterprise salary also continues to increase with the continuous development of Chinese social economy. The development environment of the market economy also changes greatly under the economic new normal and the enterprises have to reform to seek for development in the environment of economic new normal, while enterprise reform will also have great influence on the enterprise salary, so the enterprise salary also changes. The research and analysis of the reasonable increase mechanism for enterprise salary were conducted in the economic new normal in this background so as to provide feasible suggestion as well as measures for the establishment of the reasonable increase mechanism for enterprise salary.
\end{abstract}

\section{Introduction}

Chinese social economy has rapidly developed since the opening and reform. But the market economy environment also greatly changes with the progress of Chinese economy so that the former extensive economic increase way is no longer applicable to the current enterprise development and market economy construction. In recent years, Chinese economic development has been under the economic new normal and the economic development mode has also changed from the former main investment drive mode relying on the cheap labor advantage to drive the economic development to the development mode of industrial transformation and upgrading as the main economic development drive power of innovation. This transformation brings extreme profound influence on the enterprise development. For example, the enterprise salary mechanism is optimized so as to prevent the brain drain, keep talent advantage and increase the core competitiveness of the company in the transformation process of economic development mode for enterprises. Reasonable salary increase mechanism shall be established so as to facilitate and improve the operation and management for enterprises, make enterprises develop stably and long, increase the human resource benefit of enterprises, facilitate the improvement of the enterprise cohesion and drive the enterprise development.

\section{Important Meaning of Reasonable Increase of Enterprise Salary in the Economic New Normal}

Currently, Chinese economy is in the key period of transformation with major change of economic structure to have extremely profound influence on the enterprise. Many Chinese enterprises decline seriously in performance at least in the short term due to shock of the economic transformation, which brings extreme great pressure to the enterprise development. On one hand, the enterprise should adjust actively to adapt to the economic transformation; on the other hand, the performance declines to reduce the enterprise income and even lead to deficit, thus the enterprise is difficult to sustain for a period. The salary increase of enterprises will surely be impacted to a certain degree with the double pressure to cause problems such as brain drain, etc further.

The enterprise should actively increase performance to seek for development actively on one hand in the face of the important reform of Chinese economic structure transformation under the economic new normal; one the other hand, the enterprise should also actively formulate reasonable 
salary increase mechanism to facilitate its long development. This is because Chinese economic transformation is transformed from the traditional cheap labor drive to the aspect of improving quality and increasing efficiency, which means that the scientific technological content of products will be greatly increased in the future enterprise development and high requirements will be proposed on the professional knowledge and skill of staff, while staff of high quality, high level as well as strong professional knowledge and technical skills will be universal in enterprises with greater influence and how to keep these talents to prevent staff drain is closely related to the implementation of the reasonable salary increase mechanism. It is the key problem needing to be solved firstly in enterprise management and the key as well as important drive power to facilitate the long-term development of enterprises.

\section{Important Factors Affecting Reasonable Increase of Enterprise Salary under the Economic New Normal}

It has major influence on the enterprise when Chinese economy is under the transformation period to start economic new normal due to changes of economic environment. There various factors to cause influence on the reasonable increase of enterprise salary under the economic new normal and these influence factors should be comprehensively analyzed instead of focusing on the influence caused by a single factor so that good premise will be created for the establishment and implementation of the reasonable increase mechanism for Chinese enterprise salary. There are mainly three aspects to cause influence on the reasonable increase of enterprise salary in the environment of economic new normal at present and they are respectively labor, economic development and labor capital.

Influence caused by labor supply change. Chinese economy has taken the advantage of obvious cheap labor for a long period in the development process and cheap labor drive is also the main drive mode of Chinese economic development. But it is not suitable to current Chinese market environment to only pursue cheap extensive development way with the deep development of Chinese social economy and continuous improvement of market economy construction. Especially China is gradually losing the advantage of cheap labor affected by the reduction of Chinese population increase rate and aging of population. Meanwhile, China is adjusting the economic structure to facilitate the economic transformation from the cheap labor drive to the economic development way of improving the quality and increasing efficiency in efforts. In this situation, product quality is higher with high technological content and profit space continually expands to surely exert influence[1] on the reasonable increase of enterprise salary with the continuous increase of enterprise production efficiency.

The labors are continually liberated due to continual development of enterprise productivity, this supply will gradually exceed demand in the labor market, while the labor supply will have direct influence on the salary level of enterprises and decide the level to a great extent. When supply gradually exceeds demand in the labor market, the growth power of the enterprise salary is insufficient to cause difficult increase and even reduction of enterprise salary; on the contrary, when the labor force is seriously insufficient and supply is less than demand, the enterprise salary will be greatly driven by the market power to increase continually.

Great changes take place in the labor market in the key period of Chinese economic structure transformation. Chinese labor resources are reduced affected by the population policy and especially the front-line production talents of high comprehensive quality with professional knowledge and skills are seriously insufficient, so Chinese advantage of cheap labor is gradually disappearing. Chinese enterprise salary is increasing continually affected by the influence and impetus of labor supply change. The variation factor of labor supply and demand is also one of the important factors to affect reasonable increase of Chinese enterprise increase.

Influence of economic development change. The development change of the Chinese economic environment directly affects the enterprise development and it also exerts very important functions on the reasonable increase of enterprise salary. Chinese social economy has experienced the phase of rapid development since the opening and reform and the extensive development way 
can no longer adapt to the Chinese economic development with the continuous increase of economic level, so Chinese social economy stars to enter in the important structure transformation period from the extensive increase way to the way relying on the scientific and technological innovation to increase efficiency and improve quality. Chinese economic transformation is stably progressing of rapid economic development rate and overall good conditions at present to make high salary standard and facilitate the stable increase of enterprise salary. Because the salary increase level is closely related to the development of regional economy, enterprise salary increase will surely present the upward trend with the economic development in the economic environment of overall good development conditions and high development level. On the contrary, bad economic development environment will affect the operation profit of enterprises to cause insufficient impetus of enterprise salary increase, so obvious increase[2] is hard to be generated.

Because the reasonable increase of enterprise salary is closely related to the overall situation of the local regional economic development, the enterprises should fully consider local economic development factors when formulating the reasonable salary mechanism on the basis of the actual level of the regional economic development to formulate the reasonable salary increase mechanism in scientific systems so as to avoid too high or too low salary increase and brain drain due to over high expenditure of enterprise manpower cost or over low salary; both situations will surely exert extreme adverse influence on the long-term development of an enterprise so that it will lose the core competitiveness in the increasingly fierce market competition to fail to cope with all kinds of new problems possibly occurring in the economic new normal to cause failure of enterprise operation and even make it lose the existence ability.

Influence of human capital. The human capital theory was founded by the American economists Schurz and Becker in the 1960s at the earliest, which was a brand-new pioneering of the human productivity thought. Human capital refers to the capital embodied on humans, including the sum of factors including expenditure costs such as education and occupational training, etc as well as opportunity cost to receive education of producers. Its specific representation is the sum of stocks including various production knowledge, labor and management skills and health quality, etc contained in humans.

The influence and functions of human capital are more and more important in the development process of enterprise operation in the environment of economic new normal, so it also exerts more and more important influence on the increase of enterprise salary. In an enterprise, staff with higher education background and knowledge level as well as stronger professional skill level will exert more functions in its production activities, so the staff has higher salary level. In this premise, the salary increase amplitude of such staff will be much more than that of common staff.

In the reasonable increase process of enterprise salary, the salary increase amplitude of staff with higher education background and knowledge level as well as stronger professional skill level will be greater to increase human cost for enterprises. Besides, in the aspect of human resource management, because the salary increase amplitude of staff with higher education background and knowledge level as well as stronger professional skill level is great, so it is also a big challenge for enterprises in the process of human resource management on the human resource management strategy pertinent to this part of staff. To sum up, enterprises should actively adjust management strategy, adopt advanced human resource management method to facilitate the development and progress of enterprise operation, help them to adapt to Chinese economic environmental changes under the economic new normal and realize their long-term development according to the influence of human capital as well as variation of environmental factors in other aspects at the time of human resource management under the economic new normal.

Influence of salary distribution system. Salary distribution system is also an important factor to directly affect reasonable increase of enterprise salary and the core factor mean while. The salary distribution system of enterprises not only refers to salary of staff, but also includes warfare such as bonus, etc. In an enterprise, both salary standard system and the related welfare guarantee system will exert influence on the reasonable increase of its salary and the salary distribution system factor it implements should also be fully considered so $\mathrm{s}$ to guarantee that the reasonable increase 
mechanism of its salary is applicable to its specific management and operation with good practicability.

\section{Implementation Strategy to Establish Reasonable Salary Increase Mechanism in an Enterprise}

Because its reasonable salary increase mechanism needs to be executed for a long time, then it shall be reasonable and sustainable to form a system in the enterprise. So the requirements in three aspects need to be followed to establish reasonable salary increase mechanism in an enterprise so $\mathrm{s}$ to ensure that it can be thoroughly implemented in an enterprise for long to form an important component in the enterprise management system. The requirements in three sects are respectively: the salary of enterprise staff should increase with increase of economic profit; the amplitude of salary increase should be higher than that of inflation; the enterprise salary needs to be reasonably increased so that the employment will not be obviously worsened due to salary increase. The main functions of reasonable increase mechanism of enterprise salary can only be exerted to the maximum degree by reaching three principles so as to fully facilitate the development and progress of enterprises. Besides, the following aspects should also be considered in details for enterprises to establish and improve the reasonable salary increase mechanism:

Establish reasonable increase mechanism of enterprise salary according to corresponding principles. Establish reasonable increase mechanism of enterprise salary in enterprises has its own ways and certain principles should be followed to establish reasonable increase mechanism of enterprise salary besides referring to specific economic environment, actual enterprise development as well as influence factors in other aspects so $s$ to ensure the scientific nature and rationality of the mechanism with high practicability and exert active facilitated function on the enterprise development in the execution process in enterprises. At present, the reasonable increase mechanism of enterprise salary is basically established according to the following principles mainly:

Firstly, the strategic guiding principle of enterprises should be followed. Enterprises have to conduct detailed planning of the future development direction, refer to objective conditions and influence factors such as local economic development environment, enterprise development scale and economic development rule, etc to achieve long-term development and formulate enterprise development strategy through means such as assessing predictions, etc. Then corresponding reasonable increase mechanism of enterprise salary should be formulated according to the enterprise development strategy to bring out the best and facilitate each other without confliction.

Secondly, the differential incentive ways should be followed. Equalitarianism should be strictly prevented to establish reasonable increase mechanism of enterprise salary and the work initiative of enterprise staff should be motivated to create more value[4] for enterprises through salary differentiation of different posts and different work situations.

Thirdly, the fair and reasonable principle should be followed. Reasonable and scientific design should be conducted to formulate reasonable increase mechanism of enterprise salary; it should be relatively fair in the enterprise according to the principle of distribution based on work and it should be balanced with the human resource market without adverse influence and impact outside the enterprise.

Fourthly, the principle to be hooked with the enterprise profit should be followed. It should be hooked to the overall economic profit level of enterprises to formulate reasonable increase mechanism of enterprise salary. Human is an important component of an enterprise and reasonable increase mechanism of enterprise salary is an important measure to generate sense of identity and loyalty for staff on enterprises and strengthen cohesive as well centrifugal forces in enterprises. If the enterprise develops well with increased workload and increased requirements on staff in great amplitude, but the salary treatment of staff cannot be correspondingly increased, then the staff will certainly be satisfied after a long period, thus the enterprise will lose cohesive and centrifugal forces and even lose many staff to finally lose the core competitiveness in the market competition. On the contrary, if unreasonable high salary is given to staff to cause too much unreasonable cost, increased cost and lose competitive advantage for enterprises when their profits are bad, then it will be more 
difficult for them to exist and develop in the complex market economy environment.

Establish reasonable increase mechanism of enterprise salary to follow scientific and reasonable principles. It is the key to being scientific and reasonable to establish reasonable increase mechanism of enterprise salary. The following three aspects should be achieved to reach this requirement:

Firstly, enterprises need to formulate perfect assessing mechanism before establishing reasonable increase mechanism of enterprise salary and strictly execute assessment management contents so as to fully know about the work of staff in order to lay a solid foundation to formulate reasonable increase mechanism of enterprise salary and provide guarantee in the operation and management process in the enterprises.

Secondly, enterprises will bring greater pressure to its human resource management to establish reasonable increase mechanism of enterprise salary, so the construction of its human resource management department should be strengthened so that it can reasonably predict important contents such as average salary level of enterprise staff and enterprise salary increase amplitude, etc. reasonable increase target of enterprise salary should be formulated through detailed analysis of these data.

Finally, all department of an enterprise have different functions and the work content of different posts is also different, so there is difference in salary standard and performance, etc in different departments; these different posts should be classified and filed so as to ensure that fair and balanced of the overall salary increase of enterprises can be realized when the reasonable increase mechanism of enterprise salary is formulated.

Distribution scheme for important population should be established with practicability. The salary increase amplitude of important population should be allocated in priority so as to effectively motivate the work initiative of the enterprise staff and facilitate the increase of the enterprise production efficiency and the enterprises development and progress when reasonable increase mechanism of enterprise salary is formulated. For example, annual salary system is usually adopted for enterprise principals, while the amount will usually be hooked with the enterprise profit. The salary standard should be formulated according to the position level as well as the function degree on the enterprise development besides considering the important influence factor of enterprise operation profit for management personnel in enterprises at various levels, and the salary level should be finally determined to match performance assessment result meanwhile.

The formulation of the salary for the workers at the production line in the aspects of the standard and the reasonable increase amplitude in enterprises should be conducted according to objective factors such as the specific post conditions, performance level, personnel skill level of staff, etc so as to conduct differential design at certain degree to motivate the work initiative of the workers at the production line, fully use the reasonable increase mechanism of enterprise salary to stimulate the work enthusiasm of workers, increase the enterprise production efficiency, increase the profit level of human resources and facilitate the long-term development of enterprises in the premise of guaranteeing balance. Besides, enterprises should also pay attention to fully arousing the enthusiasm of staff at different levels in the enterprise so as to formulate the salary distribution mechanism most suitable to facilitate the enterprise development in combination with the differentiation and the principle of distribution based on labor on the salary scheme formulation pertinent to key population for enterprises.

Carrying out the collective salary negotiation system. The support of the collective negotiation system is also needed for enterprises to formulate internal reasonable increase mechanism of enterprise salary. Collective negotiation system refers to that a batch of enterprises jointly negotiate on issues such as the salary distribution system, form, standard and increase amplitude, etc with the staff or representatives of staff. This negotiation system facilitate the enterprises to know about the staff situation more truthfully so as to formulate scientific and reasonable salary increase mechanism Meanwhile, because the staff obtains the speaking right of salary distribution to better express their demand and opinions, better alleviate the contradictories between the enterprises and themselves and strengthen the cohesive and centrifugal forces of 
enterprises, it has positive meaning to the enterprise development.

\section{Conclusions}

Reasonable increase mechanism of enterprise salary has positive meaning to facilitate the enterprise development and progress and the enterprise development and progress will be restricted if the enterprise salary increase lacks rationality. So the influence factors of enterprise salary increase should be deeply researched so as to establish scientific and reasonable salary increase mechanism in enterprises and facilitate the enterprises top realize stable development under the economic new normal.

\section{References}

[1] He Qin, Hu Yinting, Chengyaxing. The research on influence effect of the collective negotiation system on the salary of workers at the production line in the manufacturing industry[J]. Human resources development in China, 2016(24): 63-70,94-95.

[2] Lin Jirong. Mechanism research on the reasonable increase of enterprise salary under the new normal of economic development[J]. Enterprise reform and management, 2016(17): 205-205.

[3] Wu Xiaoguang, Nie Aiqin. The current state of Chinese distribution layout imbalance and the adjusting strategy under the new normal[J]. Commercial economy research, 2016(1): 122-125.

[4] Guo Zhengmo. Can be Chinese characteristic enterprise overtime be "decent labor"---the behavior analysis on the overtime and the two transaction parties in the labor market in the enterprises[J]. Social sciences research, 2015(4): 35-40.

[5] Li Linhan, Wu Yifan. Research on optimal resident income share of economic increase based threshold model[J]. Journal of Baoding College, 2017(5): 43-49.

[6] Li Liang. Research on reasonable increase mechanism of enterprise salary under the economic new normal[D]. Hubei University of Technology, 2015. 